\title{
Placental transport of nutrients and its implications for fetal growth
}

\author{
A. W. Bell ${ }^{1}, W$. W. Hay, $\mathrm{Jr}^{2}$ and R. A. Ehrhardt ${ }^{1}$ \\ ${ }^{1}$ Department of Animal Science, Cornell University, Ithaca, NY 14853; and ${ }^{2}$ Department of \\ Pediatrics, Division of Perinatal Medicine, University of Colorado School of Medicine, \\ 4200 E. $9^{\text {th }}$ Ave, Denver, CO 80262, USA
}

\begin{abstract}
Placental growth during early and mid-pregnancy has a powerful, constraining influence on fetal growth during late pregnancy. Studies involving surgical and environmental reduction of placental size in sheep have shown an associated reduction in capacity to transport oxygen, glucose and amino acids. Oxygen transport is limited by placental blood flow but transport of glucose and amino acids is determined by the abundance and activity of specific transport proteins. Glucose transporters include the GLUT1 and GLUT3 isoforms previously identified in brain and other tissues; systems for active transport of amino acids have been inferred but not characterized. Placental metabolism of glucose and amino acids has major effects both on the quantity of carbon and nitrogen delivered to the fetus, and on the composition of substrates involved. For example, the uteroplacental tissues consume more than $60 \%$ of uterine glucose uptake during late pregnancy, and the placenta substantially modifies the pattern of amino acids delivered to fetal blood. The placenta also participates in the array of metabolic adaptations of maternal and conceptus tissues to altered maternal nutrient supply. Placental capacity for glucose transport in moderately undernourished ewes is upregulated, partly by increased expression of the GLUT3 transport protein. During more severe glucose deprivation, placental transfer and fetal uptake of glucose are constrained in proportion with maternal supply, leading to fetal growth retardation.
\end{abstract}

\section{Introduction}

The placenta is a unique organ of pregnancy of higher animals, including domestic ruminants. Its various, highly specialized functions include exchange of nutrients and excreta between mother and fetus, endocrine regulation of numerous pregnancy-specific physiological and metabolic adaptations in fetal and maternal tissues, and immunological protection of the conceptus from its maternal host. This review will address only the nutrient transport functions of the placenta.

Domestic ruminants, principally sheep, have provided most of the experimental evidence regarding placental nutrient transfer and the importance of placental influence on prenatal growth (Alexander, 1974; Battaglia and Meschia, 1988; Ferrell, 1989; Robinson et al., 1995). Unless stated otherwise, examples in this review will be confined to studies on sheep, particularly those focussed on the integration of placental function and fetal response. Major themes include relations between placental growth and capacity for nutrient transport, and placental adaptations to changing fetal nutrient requirements during gestational development and altered maternal nutrition.

\section{Placental Influences on Fetal Growth}

Growth patterns of conceptus tissues

In ruminants as in most other mammals, the major phase of placental growth occurs during the first half of gestation, substantially preceding that of fetal growth during later gestation. In the 
sheep, polycotyledonary, epitheliochorial placentation is fully established by about 30 days after conception, and the number of placentomes attached to each fetus is fixed at or soon after this time. Rapid hyperplastic grow th then occurs until about day 55 , before declining to minimal rates by midpregnancy at approximately 75 days (Ehrhardt and Bell, 1995). Placental mass (that is, total mass of placentomes) declines appreciably between mid-pregnancy and term, due to tissue dehydration, associated with loss of hyaluronic acid and related glycosaminoglycans, and extensive tissue remodelling. This pattern contrasts somewhat with that in cows, in which modest placental growth, confined to the maternal (caruncular) component, continues into the third trimester (A. W. Bell and R. A. Ehrhardt, unpublished).

\section{Effect of placental size on fetal growth}

During the latter half of pregnancy, positive correlations between fetal and placental weights become progressively stronger, such that within a few weeks of term, variation in placental weight accounts for more than $80 \%$ of variation in fetal weight (Stegeman, 1974). Such statistical associations have been used to imply, but do not necessarily prove, placental cause and fetal effect. Persuasive evidence that placental weight is indeed a powerful determinant of fetal growth during late gestation was first obtained by the deceptively elegant carunclectomy experiments of Alexander (see Alexander, 1974). In other studies, chronic heat stress, sufficient to cause persistent hyperthermia in pregnant ewes, caused a profound reduction of placental weight that was followed by fetal growth restriction (Alexander, 1974; Vatnick et al., 1991; McCrabb et al., 1993). Premating carunclectomy and maternal heat stress result in similar patterns of association between fetal and placental weights near term (Bell and Ehrhardt, 1998), suggesting that they may provide comparable models of placental insufficiency during late pregnancy.

Effects of maternal nutrition on placental growth are usually more variable and subtle than those caused by physical ablation or heat stress. Undernutrition of ewes during early and mid-pregnancy has caused conflicting positive (Faichney and White, 1987; McCrabb ef al., 1992) and negative (McCrabb et al., 1992; Clarke et al., 1998) effects on placental growth. Variation in body condition during early pregnancy may partly explain this confusion, in that fatter ewes are more likely to respond to underfeeding with a compensatory increase in placental growth, whereas the opposite occurs in lean ewes (Bell and Ehrhardt, 1998). In contrast, recent, novel studies have shown that overfeeding and rapid maternal growth of primiparous ewes during early-mid-pregnancy causes profound reductions in placental and fetal weights at term (Wallace et al., 1996; Table 1). Early indications are that the fetal growth retardation in this model of adolescent pregnancy is a consequence of placental insufficiency that is due to a primary failure of cotyledonary growth (J. M. Wallace, personal communication).

\section{Functional correlates of placental size}

In both carunclectomized and heat-treated ewes, reduction in placental size is highly correlated with decreases in several important determinants and indices of placental transport, and with consequent changes in fetal metabolic characteristics during late gestation (see reviews by Bell, 1987; Owens et al., 1989; Robinson et al., 1995; Bell and Ehrhardt, 1998). These include reductions in uterine and umbilical blood flows, consistent with reduced placental clearance of highly diffusible, flowlimited materials such as antipyrine or ethanol, and metabolic consequences such as reduced placental oxygen uptake and transport, and development of fetal hypoxaemia.

Placental capacity for glucose transport also was reduced substantially, as were uteroplacental glucose consumption rate and fetal glycaemia in carunclectomized (Owens et al, 1989) and heattreated ewes (Bell, 1987, Thureen et al., 1992). At least part of the absolute reduction in glucose transport capacity is presumed to be due to a reduction in exchange surface area of the trophoblastic membrane, as also shown in carunclectomized ewes (Robinson et al., 1995). In previously heat- 
Table 1. Fetal weight and placental variables at term in normally grown and rapidly grown adolescent ewes

\begin{tabular}{lccc}
\hline Variable & $\begin{array}{c}\text { Normally } \\
\text { grown }\end{array}$ & $\begin{array}{c}\text { Rapidly } \\
\text { grown }\end{array}$ & $\begin{array}{c}\text { Significance } \\
\text { of difference }(P)\end{array}$ \\
\hline Number of ewes & 11 & 8 & \\
Duration of gestation (days) & $143 \pm 0.3$ & $140 \pm 0.9$ & $<0.01$ \\
Fetal weight $(\mathrm{kg})$ & $4.34 \pm 0.27$ & $2.74 \pm 0.25$ & $<0.001$ \\
Placental weight $(\mathrm{g})$ & $438 \pm 44.6$ & $263 \pm 16.8$ & $<0.01$ \\
Number of placentomes & $90 \pm 7.5$ & $74 \pm 5.4$ & $\mathrm{~ns}$ \\
\hline
\end{tabular}

Values are means $\pm S E M$. $n s$ : not significant

Data from Wallace et al. (1996)

treated (Thureen et al., 1992), but not in carunclectomized (Owens et al., 1989) ewes, placental weight-specific glucose transport capacity also was reduced. This implies that chronic heat stress, which reduces average weight but not total number of placentomes, additionally reduces number or activity of specific glucose transport proteins at maternal or fetal exchange surfaces. In contrast, carunclectomy, which reduces placentome number but may stimulate a compensatory increase in average weight of individual placentomes, caused a modest increase in the placental weight-specific clearance of the nonmetabolizable glucose analogue, 3-O-methyl glucose (Owens et al., 1989). This implies that glucose transporter expression was preserved or increased in the remaining placentomes.

Placental insufficiency in heat-treated ewes also extends to impaired capacity for amino acid transport, including major reductions in placental uptake and fetal transfer of leucine, and in the normally extensive placental catabolism of this branched-chain amino acid (Ross et al., 1996). The molecular basis for the reduction in placental weight-specific transfer of leucine, and perhaps, other essential amino acids, is unknown. Presumably there is decreased abundance of specific transporter proteins, especially those responsible for active transport and concentration of amino acids in trophoblast cells (Hay, 1998),

\section{Conceptus Requirements and Placental Transport of Macronutrients}

\section{Glucose}

Glucose is a principal energy substrate for fetal and placental metabolism in ruminants (Battaglia and Meschia, 1988; Ferrell, 1989; Bell, 1993). For example, in the well-nourished, latepregnant ewe, glucose accounts for approximately $60 \%$ of the net uptake of carbon by the gravid uterus, as calculated from the data of Carver and Hay (1995) for non-nitrogenous substrates, and of Chung et al. (1998) for amino acids. Under these favourable conditions fetal glucose requirements are met entirely by placental transport and fetal uptake of glucose from the umbilical circulation. Oxidation of glucose, directly and via its fetoplacental metabolite, lactate, then accounts for about $60 \%$ of fetal ATP synthesis (see Hay, 1995).

Analysis of the kinetics of placental glucose transport in vivo has confirmed that in sheep and other species, this process is achieved by facilitated diffusion (see Hay, 1995). We have shown that the predominant glucose transporter protein isoforms in sheep placenta are GLUT1 and GLUT3, and that mRNA and protein abundance of these transporters, especially those of GLUT3, increase from mid- to late pregnancy (Ehrhardt and Bell, 1997; Table 2). This appears to account for much of the five-fold increase in glucose transport capacity of the ovine placenta in vivo over this period (Molina et al., 1991). Our failure to detect placental expression of the insulin-responsive isoform, GLUT4, is entirely consistent with the lack of a direct effect of maternal or fetal insulinaemia on uteroplacental uptake and placental transport of glucose in vivo in the pregnant ewe (see Bell, 1993; Hay, 1995). 
Table 2. Developmental changes in expression of GLUT 1 and GLUT 3 protein and RNA in the sheep placenta

\begin{tabular}{lccc}
\hline & \multicolumn{3}{c}{ Day of pregnancy } \\
\cline { 2 - 4 } Variable & 75 & 110 & 140 \\
\hline Protein abundance & & & \\
$\quad$ GLUT 1 & $1.0 \pm 0.06^{\mathrm{a}}$ & $2.1 \pm 0.19^{\mathrm{b}}$ & $2.4 \pm 0.15^{\mathrm{b}}$ \\
$\quad$ GLUT 3 & $1.0 \pm 0.04^{\mathrm{a}}$ & $1.9 \pm 0.09^{\mathrm{b}}$ & $2.9 \pm 0.09^{\mathrm{c}}$ \\
mRNA abundance & & & \\
GLUT 1 & $1.0 \pm 0.07^{\mathrm{a}}$ & $1.6 \pm 0.19^{\mathrm{b}}$ & $1.8 \pm 0.21^{\mathrm{b}}$ \\
GLUT 3 & $1.0 \pm 0.05^{\mathrm{a}}$ & $2.3 \pm 0.5^{\mathrm{b}}$ & $4.0 \pm 0.17^{\mathrm{c}}$ \\
\hline
\end{tabular}

Values are means \pm SEM in arbitrary, densitometric units expressed relative to day 75 of pregnancy.

$0 . b c$ Values with different superscripts within rows are significantly different $(P<0.05)$.

Adapted from Ehrhardt and Bell (1997)

Other possible influences on placental glucose transport include uterine and umbilical blood flow and placental glucose metabolism. Consistent with its diffusion-limited transport mechanism, the placental delivery of glucose to the umbilical circulation is not responsive to physiological variations in uterine blood flow (Wilkening et al., 1985).

\section{Amino acids}

Fetal requirements for amino acids are determined by rates of tissue growth and protein deposition that change with gestational age, and by fetal energy demands that result in extensive catabolism of amino acids throughout the latter half of gestation, even in well-nourished animals. Fractional rates of fetal tissue protein synthesis decline from approximately $25 \%$ per day at midgestation to $<10 \%$ per day near term (Kennaugh et al., 1987), concomitant with a decline in fractional rate of protein deposition from $12 \%$ per day to approximately $4 \%$ per day (Van Veen et al., 1987; Bell et al., 1989). Throughout this period, the anabolic use of amino acids is accompanied by extensive oxidative deamination and fetal ureagenesis, sufficient to support 30-35\% of fetal energy requirements (Faichney and White, 1987). Thus, placental transport of amino acid nitrogen into the umbilical circulation is considerably greater than that required for fetal synthetic purposes in sheep (Hay, 1998) and cows (Ferrell, 1989). The gestational decline in relative rates of umbilical uptake of amino acids (Bell et al., 1989) is consistent with accompanying declines in fractional rates of fetal protein synthesis (Kennaugh et al., 1987) and oxygen consumption (Bell et al., 1987).

Most amino acids taken up by the placenta are transported against a fetal-maternal concentration gradient by energy-dependent mechanisms that have been elaborated in various mammalian tissues. These mechanisms, including identity and characterization of specific transporters, have not been studied in ruminant placentae. However, it is assumed that in ruminant as in human placental microvesicles, for example, there are at least ten sodium-dependent and sodium-independent transporter systems that have different levels of activity at different placental membrane surfaces. Hay (1998) has recently summarized the specific amino acids transported by each system, conditions favouring or inhibiting or affected by each system, and location (maternal or fetal trophoblast membrane) for each system.

Known mechanisms of placental amino acid transport imply diffusion-limited rather than flow-limited clearance, and, therefore, insulation against moderate fluctuations in placental blood flow. More severe restriction of placental perfusion, as can occur during exercise or acute heat stress (Bell, 1987), may indirectly affect amino acid transport through negative effects on placental energetics and ion gradients, as discussed by Hay (1998). 


\section{Fatty acids}

Acetate and other derivatives of rumen fermentation, such as 3-hydroxybutyrate, are relatively abundant in maternal blood and are important energy sources for maternal tissues of ruminant animals (Bell, 1993). However, these short-chain fatty acids and keto acids are poorly transported by the ruminant placenta and make relatively minor contributions to fetal energy requirements in sheep and cattle (Battaglia and Meschia, 1988; Bell, 1993). The capacity for placental transport of long-chain, nonesterified fatty acids (NEFA), which are the primary vehicle for plasma delivery to other tissues of fatty acids mobilized from adipose tissue stores, is also extremely limited in sheep (Elphick et al., 1979) and, presumably, other ruminants. Regarding the adequacy of fetal supplies of the C18 essential fatty acids, Noble et al. (1985) have identified active systems for desaturation and chain-elongation of linoleic and linolenic acids in the sheep placenta. In addition, the placenta takes up and metabolizes esterified lipids from maternal plasma (Hay, 1996), which, in ruminants, are richer than plasma NEFA in linoleic and linolenic acids. Thus, placental metabolism ensures an adequate fetal supply of the longer-chain $\omega 6$ and $\omega 3$ metabolites of the C18 polyunsaturated fatty acids, which are the forms ultimately required by tissues.

\section{Impact of Placental Metabolism on Maternal-Fetal Nutrient Transfer}

\section{Oxygen consumption}

The vital role of the placenta in transporting nutrients from the maternal to the fetal bloodstream, as well as functions such as peptide synthesis and maintenance of ion gradients, have a disproportionately high metabolic cost. This greatly affects the partitioning of nutrients within the gravid uterus, as well as adding substantially to the nutrient demands of pregnancy on the dam. In the late-pregnant ewe, the aggregate weight of placentomes is less than $15 \%$ that of the attached fetus. However, the weight-specific metabolic rate of the placenta is so great that the uteroplacental tissues (placentomes, endometrium, myometrium) consume $40-50 \%$ of oxygen taken up by the uterus in ewes (Bell and Ehrhardt, 1998) and cows (Ferrell, 1989). Estimates based on measurement of uteroplacental oxygen consumption in vivo and of placental oxygen consumption in vitro suggest that neither absolute nor dry weight-specific rates of placental energy expenditure change appreciably between mid-and late gestation (Vatnick and Bell, 1992). During mid-gestation, when fetal demands are small, much of this energy presumably is used to support active placental growth, whereas in late gestation the high rate of placental ATP synthesis must be related to functional demands.

\section{Glucose metabolism}

Uteroplacental consumption accounts for $60-70 \%$ of uterine net uptake of glucose during late pregnancy in ewes (Hay, 1995) and cows (Ferrell, 1989). Glucose uptake by the entire conceptus is determined directly by the maternal arterial glucose concentration, and glucose transport to the fetus is dependent directly on the maternal-fetal concentration gradient. The transplacental glucose concentration gradient, in turn, is directly related to both placental and fetal glucose consumption. Partitioning of the uterine glucose supply into placental and fetal rates of glucose consumption, however, is dependent on the fetal glucose concentration. For example, as fetal glucose concentration decreases relative to that of the mother, increasing the maternal-fetal gradient, glucose transport to the fetus increases at the expense of placental glucose consumption (Hay, 1995).

We have recently examined the metabolic fate of glucose consumed by the ovine placenta (Aldoretta et al., 1994). Rapid metabolism to lactate (about 35\%), fructose (about $4 \%$ ), and $\mathrm{CO}_{2}$ (about $17 \%$ ) accounted for about $56 \%$ of uteroplacental glucose consumption in late-pregnant ewes with low or high maternal plasma glucose concentrations (Table 3 ). The metabolic fate of the remaining approximately $44 \%$ of glucose consumed is not known and requires investigation. Glucose oxidation accounted for $23-34 \%$ of uteroplacental oxygen consumption, depending on maternal glycaemia. 
Table 3. Effect of glucose supply on uteroplacental glucose metabolism in ewes during late pregnancy

\begin{tabular}{lcc}
\hline & \multicolumn{2}{c}{ Glucose supply } \\
\cline { 2 - 3 } Variable & \multicolumn{1}{c}{ Low } & High \\
\hline Plasma glucose concentration $\left(\mathrm{mmol} \mathrm{l}^{-1}\right)$ & $2.23 \pm 0.13$ & $4.93 \pm 0.29$ \\
Uteroplacental metabolic rates $\left(\mathrm{mmol} \mathrm{min}^{-1}\right)$ & $164 \pm 22$ & $313 \pm 39$ \\
$\quad$ Glucose consumption & $109 \pm 12$ & $182 \pm 21$ \\
Lactate production & $3.9 \pm 1.1$ & $7.0 \pm 2.5$ \\
Fructose production & $26.7 \pm 3.5$ & $42.7 \pm 7.5$ \\
Glucose oxidation & & \\
\hline
\end{tabular}

Values are means $\pm \operatorname{SEM}(n=8)$.

Data from Aldoretta et al. (1994)

Oxidizable substrates that might contribute to the remaining $66-77 \%$ of uteroplacental respiration include ketones (Carver and Hay, 1995) and acetate, at least in caruncular tissues (Bell, 1993), certain amino acids, and carbon derived from the turnover of carbohydrate and lipid stores in placental tissues. The significance of placental synthesis of lactate and fructose for fetal metabolism is reviewed elsewhere (Battaglia and Meschia, 1988; Bell, 1993; Hay, 1995). In short, umbilical uptake and fetal oxidation of these glucose-derived substrates are estimated to contribute up to $20 \%$ of fetal energy requirements, additional to the $40-50 \%$ contributed by the direct oxidation of glucose.

\section{Amino acid metabolism}

Placental metabolism substantially affects both the quantity and composition of amino acids delivered to umbilical venous blood. The turnover rate of placental constitutive proteins is very rapid but net deposition of protein is negligible during the latter half of ovine pregnancy when placental dry weight is essentially static (Ehrhardt and Bell, 1995). Nevertheless, net consumption by uteroplacental tissues of glutamate, serine, and the branched chain amino acids is appreciable (Liechty et al., 1991; Chung et al., 1998), implying significant catabolism or transamination of these acids. An additional, small fraction of this net loss of amino acids will be in the form of secreted peptides. Placental net catabolism was estimated recently to account for $24 \%$ of uterine uptake of amino acid nitrogen in well-fed, late-pregnant ewes (Chung et al., 1998).

The ovine placenta has very little enzymatic capacity for urea synthesis but produces considerable amounts of ammonia, much of which is released into maternal and, to a lesser extent, fetal circulations (see Hay, 1998). This is consistent with reports of extensive placental deamination of branched chain amino acids to their respective keto acids, which are released into fetal and maternal bloodstreams (Smeaton et al., 1989; Loy et al., 1990), and with rapid rates of glutamate oxidation in the placenta (Moores et al., 1994).. Transamination of branched chain amino acids accounts for some of the net glutamate acquisition by the placenta, the remainder of which is taken up from the umbilical circulation (Moores et al., 1994). That which is not quickly oxidized combines with ammonia to synthesize glutamine, which is then released back into the umbilical bloodstream (Chung et al., 1998). Some of this glutamine is converted back to glutamate by the fetal liver, which produces most of the glutamate consumed by the placenta (Vaughn et al., 1995). This establishes a glutamate-glutamine shuttle which promotes placental oxidation of glutamate and fetal hepatic utilization of the amide group of glutamine.

Another example of the influence of placental metabolism on the pattern of amino acids delivered to the fetus is the almost quantitative conversion of serine, mostly taken up from maternal blood, to glycine by the placenta (Chung et al., 1998). This reconciles earlier observations of major discrepancies between negligible net uptake of glycine by the uterus and substantial net release of 
Table 4. Maternal weight change, fetal weight, and indices of placental glucose transport at day 135 of pregnancy in ditocous ewes fed 100\% (Fed) or 60\% (Underfed) of predicted energy requirements for the preceding 14 days

\begin{tabular}{|c|c|c|c|c|}
\hline Variable & Fed & Underfed & PSE & $\begin{array}{l}\text { Significance of } \\
\text { difference }(P)\end{array}$ \\
\hline$\Delta$ maternal weight $(\mathrm{kg})$ & 5.3 & -2.7 & 1.0 & $<0.001$ \\
\hline Fetal weight (kg) & 3.58 & 3.46 & 0.16 & ns \\
\hline \multicolumn{5}{|l|}{ Plasma glucose $\left(\mathrm{mmol} \mathrm{l}^{-1}\right)$} \\
\hline Maternal & 3.72 & 2,84 & 0.09 & $<0.001$ \\
\hline Fetal & 0.57 & 0.49 & 0.03 & $<0.05$ \\
\hline Maternal-fetal gradient & 3.15 & 2.33 & 0.03 & $<0.001$ \\
\hline \multicolumn{5}{|l|}{ Placental 3MG clearance } \\
\hline ( $\mathrm{ml} \mathrm{min} \mathrm{m}^{-1} \mathrm{~kg}^{-1}$ placental weight) & 117 & 176 & 7 & $<0.001$ \\
\hline $\mathrm{CB}$ sites (pmol mg-1 protein) & 105 & 126 & 3 & $<0.01$ \\
\hline \multicolumn{5}{|l|}{ GLUT protein (arbitrary units) ${ }^{a}$} \\
\hline GLUT 1 & 1.00 & 0.83 & 0.06 & ns \\
\hline GLUT 3 & 1.00 & 1.19 & 0.04 & $<0.05$ \\
\hline
\end{tabular}

Values are means $(n=5)$.

PSE: pooled standard error; ns: not significant; 3MG:3-O-methyl glucose; $\mathrm{CB}$ : cytochalasin B binding sites. AExpresssed relative to Fed group.

Adapted from Ehrhardt (1997)

this amino acid into the umbilical circulation (see Hay, 1998). In addition to ensuring a supply of the most abundant amino acid in fetal blood, this process is important for placental purine synthesis via the donation of the side-chain $\beta$-carbon atom of serine to form methylenetetrahydrofolate.

\section{Placental Adaptations to Altered Supplies of Energy and Nitrogen}

Maternal nutrition is often uncertain and variable, especially in extensively managed ruminant herds and flocks, with potential effects on fetal nutrient supply, growth and well-being, particularly during late pregnancy. Domestic ruminants, like other mammals, have developed various adaptive mechanisms to ameliorate the direct impact on fetal growth and development of all but the most serious nutritional vagaries. Some of these involve altered responses of maternal tissues such as liver, adipose tissue, and muscle to insulin and, possibly, other regulatory hormones. The net result is substitution of NEFA for glucose as energy sources in maternal insulin-responsive tissues, and increased availability of glucose for insulin-independent uptake by the placenta (Bell, 1993; Bell and Bauman, 1997). Fetal metabolic adaptations become necessary when maternal and placental responses fail to maintain a fully adequate fetal glucose supply (Bell, 1993; Hay, 1996). These include induction of hepatic gluconeogenesis, increased reliance on amino acids as a primary energy source, and, inevitably, reduced rates of protein synthesis and growth.

\section{Glucose transport and metabolism}

We recently tested the idea that the placenta is more than a passive beneficiary of maternal metabolic adaptations designed to support fetal glucose uptake in the face of a fluctuating maternal energy supply. Various indices of placental glucose transport capacity were compared in well-fed and moderately undernourished, ditocous ewes during late pregnancy (Ehrhardt, 1997). Results are summarized in Table 4. Restriction of maternal energy intake to $60 \%$ of predicted requirements for 2 weeks caused moderate maternal and fetal hypoglycaemia and a $26 \%$ decrease in maternal-fetal 
glucose concentration gradient. In these ewes, placental glucose transport capacity, assessed in vivo by measurement of clearance of the nonmetabolizable analogue, 3-O-methyl glucose, was increased $50 \%$ over values in well-fed ewes. Estimation of placental glucose transporter abundance in vitro by binding of cytochalasin B, and by the concentration of the GLUT3 transport protein as measured by Western blotting, were each increased by about $20 \%$; concentration of the other major placental glucose transporter isoform, GLUT1, was unchanged. The effectiveness of these adaptations was indicated by unimpaired fetal growth in the underfed ewes (Table 4).

During more severe maternal undernutrition or starvation for several days, the ability to repartition maternal glucose in favour of the conceptus becomes limited and uterine and umbilical net uptake of glucose dwindle directly with the decline in maternal glucose supply (Bell, 1993; Hay, 1995). Under these conditions, the development of profound fetal hypoglycaemia helps to sustain the maternal-fetal gradient in glucose concentration by restricting the reverse transfer of glucose to the placenta, and reducing placental glucose consumption (Hay, 1995). More specific manipulation of maternal and fetal glycaemia by prolonged maternal infusion with insulin has shown that the decline in fetal glucose concentration is not proportional to that of the mother. This tends to decrease the maternal-fetal glucose concentration gradient, protecting placental glucose consumption at the expense of the fetus. In response, fetal glucose needs are diminished by a reduction in fetal growth rate (Carver and Hay, 1995).

\section{Amino acid transport and metabolism}

Fasting ewes for 5 days during late pregnancy had relatively little effect on placental delivery of amino acids to the fetus despite significant reductions in maternal plasma concentrations of many amino acids (Lemons and Schreiner, 1983). This suggests that during short term energy or protein deprivation, placental mechanisms for active transport of amino acids are unimpaired and may even be upregulated. Under similar fasting conditions, the uteroplacental deamination of branched chain amino acids appeared to be increased, as judged from a threefold increase of the efflux of $\alpha$ ketoisocaproate into uterine and umbilical circulations (Liechty et al., 1991). This finding suggests that increased protein catabolism and amino acid oxidation may partly substitute for the likely reduction in placental glucose oxidation under these conditions.

Placental responses to more prolonged restriction of energy or protein have not been investigated. However, in ewes fed adequate energy but insufficient protein during the last month of pregnancy, fetal growth and protein deposition over this period were reduced by $18 \%$ (McNeill et al., 1997). This finding implies that neither maternal mobilization of labile protein stores nor putative adaptations in placental capacity for amino acid transport were sufficient to offset a $50 \%$ reduction in maternal supply of absorbed amino acids.

\section{Conclusions}

In healthy, well-managed ruminants, the placenta exerts an appropriate constraint on fetal growth during late gestation. When environmental factors, including matemal nutrition, retard placental development, associated reductions in nutrient transport capacity can lead to fetal growth retardation. Normal regulation and environmental modulation of early placental growth appear to be critically important in this regard, but are poorly understood. Recent observations of placental stunting in overfed adolescent ewes (Wallace et al, 1996) offer an intriguing model for further study. The specific aspect(s) of placental nutrient transport that are normally most limiting have not been conclusively defined. However, it is revealing that even in very well-fed, monotocous ewes, direct fetal infusion with glucose during the last month of gestation caused an $18 \%$ increase in birth weight of lambs (Stevens et al, 1990). Identification of the specific proteins responsible for placental glucose transport, together with early evidence for their molecular regulation, offer possibilities for more fundamental studies of gene expression. The complexity of placental transport systems for amino 
acids has so far defied detailed investigation in ruminants. The unique importance of amino acids as substrates for both fetal growth and oxidative metabolism demands serious study of the means by which their placental transfer is regulated.

\section{References}

Aldoretta PW, Gresores A and Hay WW, Jr (1994) Effect of glucose supply on ovine uteroplacental glucose utilization, oxidation, and lactate production Proceedings of the Society for Gynecological Investigation p 138 (Abstract 0104)

Alexander G (1974) Birth weight of lambs: influences and consequences. In Size at Birth pp 215-245 Eds K Elliot and J Knight. Elsevier, Amsterdam

Battaglia FC and Meschia G (1988) Fetal nutrition Ammal Revierv of Nutrition 8 43-61

Bell AW (1987) Consequences of severe heat stress for fetal development. In Heat Stress: Physical Exertion and Environment pp 313-333 Eds JRS Hales and DAB Richards. Elsevier, Amsterdam

Bell AW (1993) Pregnancy and fetal metabolism. In Quantitative Aspects of Ruminant Digestion and Metabolism pp 405-431 Eds JM Forbes and J France. CAB International, Wallingford

Bell AW and Bauman DE (1997) Adaptations of glucose metabolism during pregnancy and lactation journal of Mammary Gland Biology and Neoplasia 2 265-278

Bell AW and Ehrhardt RA (1998) Placental regulation of nutrient partitioning during pregnancy. In Nutrition and Reproduction pp 229-254 Eds GA Bray, W Hansel and DH Ryan. Louisiana State University Press, Baton Rouge.

Bell AW, Battaglia FC and Meschia G (1987) Relation between metabolic rate and body size in the ovine fetus lournal of Nutrition 117 1181-1186

Bell AW, Kennaugh JM, Battaglia FC and Meschia G (1989) Uptake of amino acids and ammonia at mid-gestation by the fetal lamb Quarterly Journal of Experimental Physiology 74 635-643

Carver TD and Hay WW, Jr (1995) Uteroplacental carbon substrate metabolism and $\mathrm{O}_{2}$ consumption after long-term hypoglycemia in pregnant sheep American lournal of Physiology 269 E299-E308

Chung M, Teng C, Timmerman M, Meschia G and Battaglia FC (1998) Production and utilization of amino acids by ovine placenta in vizo. American Journal of Physiology 274 E13-E22

Clarke L, Heasman L, Juniper DT and Symonds ME (1998) Maternal nutrition in early-mid gestation and placental size in sheep British fournal of Nutrition 79 359-364

Ehrhardt RA (1997) Regulation of Glucose Transport and Partifioning by the Placenta in the Second Half of Pregnancy in Sheep, PhD Dissertation, Comell University, Ithaca NY

Ehrhardt RA and Bell AW (1995) Growth and metabolism of the ovine placenta during mid-gestation Placenta 16 727-741

Ehrhardt RA and Bell AW (1997) Developmental increases in glucose transporter concentration in the sheep placenta American Totinal of Plysiology 273 R1132-R1141

Elphick MC, Hull D and Broughton Pipkin F (1979) The transfer of fatty acids across the sheep placenta fournal of Developmental Physiology $131-45$

Faichney GJ and White GA (1987) Effects of maternal nutritional status on fetal and placental growth and on fetal urea synthesis in sheep Australian Formal of Biological Sciences 40 365-377

Ferrell CL (1989) Placental regulation of fetal growth. In Animal
Growth Regulation pp 1-19 Eds DR Campion, GJ Hausman and RJ Martin. Plenum Press, New York

Hay WW, Jr (1995) Regulation of placental metabolism by glucose supply Reproduction. Fertility and Development 7 365-375

Hay WW, Jr (1996) Nutrition and development of the fetus: carbohydrate and lipid metabolism. In Nutrition in Pediatrics pp 364-378 Eds WA Walker and JB Watkins. BC Decker, Hamilton

Hay WW, Jr (1998) Fetal requirements and placental transfer of nitrogenous compounds. In Feial and Neonatal Physiology (2nd Edn) PP 619-634 Eds RA Polin and WW Fox. Saunders, Philadelphia

Kennaugh JM, Bell AW, Teng C, Meschia G and Battaglia FC (1987) Ontogenetic changes in the rates of protein synthesis and leucine oxidation during fetal life Pediatric Research 22 688-692

Lemons JA and Schreiner RL (1983) Amino acid in the ovine fetus American Journal of Physiology 244 E459-E466

Liechty EA, Kelley J and Lemons JA (1991) Effect of fasting on uteroplacental amino acid metabolism in the pregnant sheep Biology of the Neonate 60 207-214

Loy GL, Quick AN, Jr, Hay WW, Jr, Meschia G, Battaglia FC and Fennessey FC (1990) Fetoplacental deamination and decarboxylation of leucine American Joumal of Physiology 259 E492-E497

McCrabb G], Egan AR and Hosking BJ (1992) Maternal undernutrition during mid-pregnancy in sheep: variable effects on placental growth Joumal of Agriculfural Science. Cambridge 118 127-132

McCrabb GJ, McDonald BJ and Hennoste LM (1993) Heat stress during mid-pregnancy in sheep and the consequences for placental and fetal growth Joumal of Agricultural Science, Cambridge 120 265-271

McNeill DM, Slepetis R, Ehrhardt RA, Smith DM and Bell AW (1997) Protein requirements of sheep in late pregnancy: partitioning of nitrogen between gravid uterus and maternal tissues Journal of Animal Science 75 809-816

Molina RD, Mechia G, Battaglia FC and Hay WW, Jr (1991) Gestational maturation of placental glucose transfer capacity in sheep American fournal of Physiology 261 R697-R704

Moores RR, Jr, Vaughn PR, Battaglia FC, Fennessey PV, Wilkening RB and Meschia G (1994) Glutamate metabolism in the fetus and placenta of late-gestation sheep American Journal of Physiology 267 R89-R96

Noble RC, Shand, JH and Christie WW (1985) Synthesis of C20 and $\mathrm{C} 22$ polyunsaturated fatty acids by the placenta of the sheep Biology of the Neonate 47 333-338

Owens JA, Owens PC and Robinson JS (1989) Experimental growth retardation: metabolic and endocrine consequences. In Research in Perinatal Medicine VIII. Adeances in Fetal Physiology pp 263-286 Eds PD Gluckman, BM Johnston and PW Nathanielsz. Perinatology Press, Ithaca

Robinson J, Chidzanja S, Kind K, Lok F, Owens P and Owens J (1995) Placental control of fetal growth Reproduction, Fertility and Developuerit 7 333-344

Ross JC, Fennessey PV, Wilkening RB, Battaglia FC and Meschia G 
(1996) Placental transport and fetal utilization of leucine in a model of fetal growth retardation American foumal of Physiology 270 E491-E503

Schneider H (1991) Placental transport function Reproduction, Fertility and Development 3 345-353

Smeaton IC, Owens JA, Kind KL and Robinson JS (1989 The placenta releases branched-chain keto acids into the umbilical and uterine circulations in the pregnant sheep Journal of Developmental Physiology 12 95-99

Stegeman JHG (1974) Placental development in the sheep and its relation to fetal development Bijdragen fot de Dierkunde 44 1-72

Stevens D, Alexander G and Bell AW (1990) Effect of prolonged glucose infusion into fetal sheep on body growth, fat deposition and gestation length Journal of Developmental Physiology 13 277-281

Thureen P, Trembler KA, Meschia G, Makowski EL and Wilkening RB (1992) Placental glucose transport in heat-induced fetal growth retardation American Joutnal of Physiology 263 R578- R585 van Veen LCP, Teng C, Hay WW, Jr, Meschia G and Battaglia FC (1987) Leucine disposal and oxidation rates in the fetal lamb Metabolism 36 48-53

Vatnick I and Bell AW (1992) Ontogeny of hepatic and placental growth and metabolism in sheep American Journal of Physiology 263 R619-R623

Vatnick I, Ignotz G, McBride BW and Bell AW (1991) Effect of heat stress on ovine placental growth in early pregnancy Journal of Developmental Physiology 16 163-166

Vaughn PR, Lobo C, Battaglia FC, Fennessey PV, Wilkening RB and Meschia G (1995) Glutamine-glutamate exchange between placenta and fetal liver American Jotumal of Physiology 268 E705-E711

Wallace JM, Aitken RP and Cheyne MA (1996) Nutrient partitioning and fetal growth in rapidly growing adolescent ewes Journal of Reproduction and Fertility 107 183-190

Wilkening RB, Battaglia FC and Meschia G (1985) The relationship of umbilical glucose uptake to uterine blood flow Journat of Developmental Physiology 7 313-331 